\title{
Morbidity after traumatic spinal injury in pediatric and adolescent sports-related trauma
}

\author{
*Saksham Gupta, BA, ${ }^{1}$ Blake M. Hauser, BS, MPhil, ${ }^{1}$ Mark M. Zaki, BS, BA,, Edward Xu, BS, \\ David J. Cote, BS, ${ }^{1,2}$ Yi Lu, MD, PhD, ${ }^{1}$ John H. Chi, MD, MPH, ${ }^{1}$ Michael Groff, MD, ${ }^{1}$ \\ Ayaz M. Khawaja, MD, ${ }^{1,2}$ Mitchel B. Harris, MD, ${ }^{3}$ Timothy R. Smith, MD, PhD, MPH, ${ }^{1}$ and \\ Hasan A. Zaidi, MD1
}

\begin{abstract}
${ }^{1}$ Computational Neurosciences Outcomes Center, Department of Neurosurgery, Brigham and Women's Hospital, Harvard Medical School; ${ }^{2}$ Channing Division of Network Medicine, Department of Medicine, Brigham and Women's Hospital, Harvard Medical School; and 'Department of Orthopedics, Massachusetts General Hospital, Harvard Medical School, Boston, Massachusetts
\end{abstract}

OBJECTIVE Sports injuries present a considerable risk of debilitating spinal injury. Here, the authors sought to profile the epidemiology and clinical risk of traumatic spinal injuries (TSIs) in pediatric sports injuries.

METHODS The authors conducted a retrospective cohort analysis of pediatric patients who had experienced a sportsrelated TSI, including spinal fractures and spinal cord injuries, encoded in the National Trauma Data Bank in the period from 2011 to 2014.

RESULTS Included in the analysis were 1723 cases of pediatric sports-related TSI, which represented $3.7 \%$ of all pediatric sports-related trauma. The majority of patients with TSI were male (81\%), and the median age was 15 years (IQR 13-16 years). TSIs arose most often from cycling accidents (47\%) and contact sports (28\%). The most frequently fractured regions were the thoracic (30\%) and cervical (27\%) spine. Among patients with spinal cord involvement (SCI), the cervical spine was involved in $60 \%$ of cases.

The average length of stay for TSIs was 2 days (IQR $1-5$ days), and $32 \%$ of the patients required ICU-level care. Relative to other sports-related trauma, TSIs without SCI were associated with an increased adjusted mean length of stay by 1.8 days $(95 \% \mathrm{Cl} 1.6-2.0$ days), as well as the need for ICU-level care (adjusted odds ratio [aOR] 1.6, 95\% $\mathrm{Cl} 1.3-1.9)$. Also relative to other sports-related trauma, TSls with SCl had an increased length of stay by 2.1 days $(95 \% \mathrm{Cl} 1.8-2.6$ days) and the need for ICU-level care (aOR 3.6, 95\% Cl 2.6-4.8).

TSIs without SCI were associated with discharge to or with rehabilitative services (aOR 1.7, 95\% Cl 1.5-2.0), as were TSls with $\mathrm{SCl}(\mathrm{aOR} 4.0,95 \% \mathrm{Cl} 3.2-4.9)$, both relative to other sports-related trauma. Among the patients with TSIs, predictors of the need for rehabilitation at discharge were having a laminectomy or fusion, concomitant lower-extremity injury, head injury, and thoracic injury. Although TSIs affected $4 \%$ of the study cohort, these injuries were present in $8 \%$ of patients discharged to or with rehabilitation services and in $17 \%$ of those who died in the hospital.

CONCLUSIONS Traumatic sports-related spinal injuries cause significant morbidity in the pediatric population, especially if the spinal cord is involved. The majority of TSI cases arose from cycling and contact sports accidents, underscoring the need for improving education and safety in these activities.

https://thejns.org/doi/abs/10.3171/2019.10.SPINE19712

KEYWORDS pediatric spinal injury; sports injury; rehabilitation; trauma; spinal cord injury

$\mathrm{T}$ Raumatic spinal injuries (TSIs) are acute insults to the vertebral column and spinal cord that can be physically and mentally debilitating. The incidence of TSIs in the pediatric population is estimated at below $2 \%$ per year, although they can be a major cause of morbidity. ${ }^{33}$ Pediatric patients with TSIs with spinal cord involvement (SCI) are more likely to recover than adults with the same injuries, but the majority of these pediatric patients will still experience some degree of transient or permanent disability. ${ }^{41}$ Further, these injuries require ex-

ABBREVIATIONS AIS = Abbreviated Injury Scale; aOR = adjusted odds ratio; NTDB = National Trauma Data Bank; SCI = spinal cord involvement; TBI = traumatic brain injury; TSI = traumatic spinal injury.

SUBMITTED June 16, 2019. ACCEPTED October 14, 2019.

INCLUDE WHEN CITING Published online December 27, 2019; DOI: 10.3171/2019.10.SPINE19712.

* S.G. and B.M.H. share first authorship of this paper. 
tensive imaging workup when they do occur, which can contribute to the financial burden. ${ }^{29}$

In the pediatric population, motor vehicle accidents are the most common cause of TSI, followed by sports injuries. ${ }^{5,13,33,35}$ Teenage and young adult males are at highest risk for TSIs, especially in the setting of recreational and contact sports. ${ }^{16,18,33,35}$ The recent finding of chronic traumatic encephalopathy in American football players has brought increased attention and harm-reduction strategies to traumatic brain injury (TBI) in contact sports. ${ }^{30,40}$ However, the literature on sports-related TSI remains sparse in comparison to that on TBI. In the present nationwide cohort study, we sought to profile the epidemiology, outcomes, and risk factors for TSI in pediatric sports and recreational injuries.

\section{Methods \\ Data Source}

We utilized the National Trauma Data Bank (NTDB) databases with a focus on the period from 2011 to 2014. This is a prospectively collected and validated database that includes trauma facilities across the country. The NTDB has been used extensively to study TBI and TSI, among other trauma types..$^{17,21,35,37,42}$

\section{Study Design}

This is a retrospective multicenter cohort study utilizing a prospectively collected nationwide registry. The exposures of interest were TSI with and without SCI in the setting of all sports-related trauma.

\section{Inclusion and Exclusion Criteria}

Inclusion criteria consisted of 1) an age between 0 and 17 years at the time of injury, 2) an ICD-9 external cause of injury code corresponding to a sports-related or recreational injury (Supplemental Appendix 1), and 3) an ICD-9 diagnosis of a spinal fracture or cord injury. Sports-related injuries were further stratified into watersport/swimming, skiing/snowboarding, skateboarding/rollerblading, cycling, contact sports, and other injuries. Contact sports injuries, in particular, were defined as ICD-9 external causes of injury corresponding to American football, rugby, and physical contact with another player or object used in the game causing trauma, as well as ICD-9 external cause of injury codes for pushing, shoving, and running into players or objects during sport. Cycling sports injuries did not include ICD-9 external causes of injury corresponding to recreational motorized vehicles, as these were believed to align more closely with motor vehicle accidents. However, cyclists struck by motorized vehicles were counted as cyclists for the purposes of this analysis. Skateboarders and rollerbladers struck by motorized vehicles were also included.

\section{Covariates and Outcomes}

Pertinent covariates and outcome variables were extracted from the NTDB. Covariates were included for descriptive statistics and to control for confounding. These included the demographic characteristics of age, sex, race, ethnicity, insurance (including Medicaid, other governmental plans, no-fault automobile, private/commercial insurance, self-pay, and other nongovernmental plans), and region (Midwest, South, West, and Northeast); and the clinical characteristics of specific spinal injuries, concomitant head and bodily injuries (rated according to the Abbreviated Injury Scale [AIS], categorized into head, face, neck, thoracic, abdominal, upper-extremity, and lower-extremity injuries), skull base fractures, comorbidities linked to bone strength with a prevalence over $0.1 \%$, and hypotension (systolic blood pressure under $90 \mathrm{~mm} \mathrm{Hg}$ ) on presentation.

Our primary outcome of interest was discharge with the need for rehabilitation as a proxy for functional status at discharge. This outcome included discharge to home with services, discharge to a short- or long-term rehabilitation facility, and transfer to another inpatient hospital. We assumed that those patients who required transfer for a higher level of care would require some level of rehabilitation after discharge. Secondary outcomes included ICU admission, overall length of stay, and in-hospital mortality.

\section{Statistical Analysis}

We first calculated descriptive statistics using t-tests for continuous variables and chi-square tests for categorical variables. Continuous variables are presented as medians with interquartile ranges. We then applied multivariable linear and logistic regression to construct adjusted mean estimates and odds ratios (aORs) to determine the effect of injuries on dispositional outcomes. Within regression models, we adjusted for age (with linear and quadratic terms), sex, race, ethnicity, insurance, region, Glasgow Coma Scale score, hypotension, concomitant nonspinal injuries diagnosed in AIS zones, and ICD-9 coding to adjust for possible confounding effects of demographic characteristics, injury severity, and other bodily injuries. All statistical analyses were conducted using $\mathrm{R}$ version 3.3.3 (R Foundation for Statistical Computing). A p value $<0.05$ was considered statistically significant.

\section{Missing Data}

We applied multiple imputation utilizing the Amelia package in $\mathrm{R}$, which applies the expectation-maximization with bootstrapping algorithm for multiple ratio imputation. ${ }^{20}$ We constructed 10 imputed data sets using demographic and clinical characteristics, injuries (including TSIs and other traumas), procedural need, and disposition. Estimates presented in the results are pooled from the 10 resulting imputed data sets.

\section{Results}

\section{Demographic and Presenting Features}

We included 46,009 cases of pediatric sports-related trauma; of these, 1723 (3.7\%) were pediatric sports-related TSIs (Table 1). The median age of the TSI cases was 15 years (IQR 13-16 years), and $81 \%$ of cases were male. The majority of the patients were identified as white $(71.8 \%)$ and non-Hispanic (72.3\%). Patients most commonly paid with private and commercial insurance $(53.7 \%)$.

The mechanisms of injury in the TSI cohort included 
cycling injuries (46.6\%), contact sports injuries (28.4\%), skiing and snowboarding accidents (16.2\%), and skateboarding and rollerblading accidents (4.6\%), among others. As age increased, all sports injuries became more frequent (Fig. 1). Cycling injuries caused the most injuries in all age groups; in the group between 14 and 17 years old, this mechanism of injury was followed in frequency by contact sports and skateboarding/rollerblading injuries.

TSIs had SCI in $25.2 \%$ of cases. In total, these injuries involved the cervical, thoracic, lumbar, and sacrococcygeal regions in $38.5 \%, 32.8 \%, 25.8 \%$, and $13.1 \%$ of cases, respectively. The majority of injuries occurred in one spinal region only, which was especially true for cervical spine injuries (Fig. 2). The most frequently fractured spine region was the thoracic spine (30.1\%), and the most frequent region with SCI was the cervical spine (60\% of all TSIs with SCI). A total of 720 cases had concomitant head injury (41.8\%). The median AIS score for TSI patients was 9 (IQR 5-16) compared to 4 (IQR 4-9) for nonTSI patients. While $8 \%$ of TSI patients were hypotensive on presentation, $16 \%$ of non-TSI cases were hypotensive.

\section{Hospital Course}

TSIs necessitated hospital admission in a majority of cases (83.9\%) and ICU admission in nearly one-third of cases $(32.2 \%)$. Compared to non-TSIs, TSIs were more frequently associated with the need for ICU care, regardless of SCI status (Fig. 3). Relative to non-TSI, the need for ICU admission was associated with TSI with SCI (aOR $3.6,95 \%$ CI 2.6-4.8) and without SCI (aOR 1.6, 95\% CI $1.3-1.9)$.

Among patients with TSIs, $6.8 \%$ and $1.4 \%$ required fusion and laminectomy, respectively. In particular, respective rates were $8.8 \%$ and $1.6 \%$ for patients with spine fractures and $1.5 \%$ and $14.1 \%$ for patients with cervical spine fractures. Among all injury mechanisms, these rates were highest for skiing and snowboarding injuries at $12.3 \%$ for fusion and 3.3\% for laminectomy. The adjusted length of stay was longer for TSIs without and with SCI by 1.8 and 2.1 days, respectively, compared to patients without TSI (both $\mathrm{p}<0.001$ ). The average total length of stay for patients who required laminectomy or fusion was 10.0 days.

\section{Hospital Disposition}

Patients who were discharged to rehabilitative care or to home with rehabilitative services represented $21.8 \%$ of discharges for TSI and 9.5\% of discharges for sportsrelated non-TSI. Moreover, TSIs without and with SCI were associated with discharge to or with rehabilitation (aOR 1.7, 95\% CI 1.5-2.0 and aOR 4.0, 95\% CI 3.2-4.9, respectively; Fig. 3), both relative to other sports-related trauma. Among the patients with TSIs, laminectomy (aOR $3.8,95 \%$ CI 1.5-9.8), fusion (aOR 3.7, 95\% CI 2.3-5.8), concomitant lower-extremity injury (aOR 2.1, 95\% CI 1.5-2.8), head injury (aOR 1.9, 95\% CI 1.5-2.5), and thoracic injury (aOR 1.7, 95\% CI 1.2-2.3) were each associated with discharge to or with rehabilitation. Age, sex, race, ethnicity, insurance, obesity, other concomitant injuries, hypotension, and type of sport were not statistically significant predictors in this multivariable model.
TABLE 1. Demographic and clinical characteristics of pediatric sports-related TSI and non-TSI cases

\begin{tabular}{|c|c|c|c|}
\hline Variable & TSI $(n=1723)$ & $\begin{array}{c}\text { Non-TSI } \\
(n=44,286)\end{array}$ & $\begin{array}{c}p \\
\text { Value }\end{array}$ \\
\hline Median age (IQR) & $15(13-16)$ & $12(9-15)$ & $<0.001$ \\
\hline \multicolumn{4}{|l|}{ Sex, no. $(\%)$} \\
\hline Male & $1,397(81.1)$ & $35,199(79.5)$ & 0.112 \\
\hline Female & $325(18.9)$ & $9,064(20.5)$ & \\
\hline Unknown & $1(0.1)$ & $23(0.1)$ & \\
\hline \multicolumn{4}{|l|}{ Race, no. (\%) } \\
\hline White & $1,237(71.8)$ & $29,238(66.0)$ & $<0.001$ \\
\hline Black & $189(11.0)$ & $5,833(13.2)$ & \\
\hline Asian & $30(1.7)$ & $834(1.9)$ & \\
\hline Other & $191(11.1)$ & $5,906(13.3)$ & \\
\hline Unknown & $76(4.4)$ & $2,475(5.6)$ & \\
\hline \multicolumn{4}{|l|}{ Ethnicity, no. (\%) } \\
\hline Hispanic & $188(10.9)$ & $5,873(13.3)$ & $<0.001$ \\
\hline Not Hispanic & $1,246(72.3)$ & $29,667(67.0)$ & \\
\hline Unknown & $289(16.8)$ & $8,746(19.7)$ & \\
\hline \multicolumn{4}{|l|}{ Insurance, no. (\%) } \\
\hline Private insurance & $926(53.7)$ & $21,700(49.0)$ & $<0.001$ \\
\hline Medicaid & $374(21.7)$ & $13,390(30.2)$ & \\
\hline Self-pay & $94(5.5)$ & $2,527(5.7)$ & \\
\hline No-fault automobile & $103(6.0)$ & $1,134(2.6)$ & \\
\hline Other, government & $49(2.8)$ & $1,238(2.8)$ & \\
\hline Other, nongovernmental & $55(3.2)$ & $1,312(3.0)$ & \\
\hline Unknown & $122(7.1)$ & $2,985(6.7)$ & \\
\hline \multicolumn{4}{|l|}{ Concomitant trauma, no. (\%) } \\
\hline Head injury & $720(41.8)$ & $16,878(38.1)$ & 0.002 \\
\hline Face injury & $395(22.9)$ & $9,401(21.2)$ & 0.098 \\
\hline Neck injury & $35(2.0)$ & $356(0.8)$ & $<0.001$ \\
\hline Abdominal injury & $274(15.9)$ & $6,307(14.2)$ & 0.058 \\
\hline Thoracic injury & $397(23.0)$ & $2,849(6.4)$ & $<0.001$ \\
\hline Upper-extremity injury & $375(21.8)$ & $15,290(34.5)$ & $<0.001$ \\
\hline Lower-extremity injury & $522(30.3)$ & $12,900(29.1)$ & 0.308 \\
\hline Obesity, no. (\%) & $27(1.6)$ & $403(0.9)$ & 0.008 \\
\hline
\end{tabular}

$\mathrm{n}=$ number of patients.

In-hospital death occurred in $2.9 \%$ of patients with TSI and $0.5 \%$ of those without TSI. Moreover, TSI without and with SCI was associated with discharge to hospice or in-hospital mortality (aOR 1.7, 95\% CI 1.2-2.6 and aOR 2.4, 95\% CI 1.2-4.7, respectively; Fig. 3). Predictors of inhospital mortality or discharge to hospice included concomitant head injury (aOR 4.8, 95\% CI 1.7-13.6), thoracic injury (aOR 3.5, 95\% CI 1.7-7.1), and hypotension (aOR 3.5, 95\% CI 1.7-7.1). Age, sex, race, ethnicity, insurance, obesity, other concomitant injuries, hypotension, and type of sport were not statistically significant predictors in this multivariable model. TSIs with SCI, compared to those without SCI, were statistically significantly associated with the need for ICU admission and rehabilitation, but not with death. 


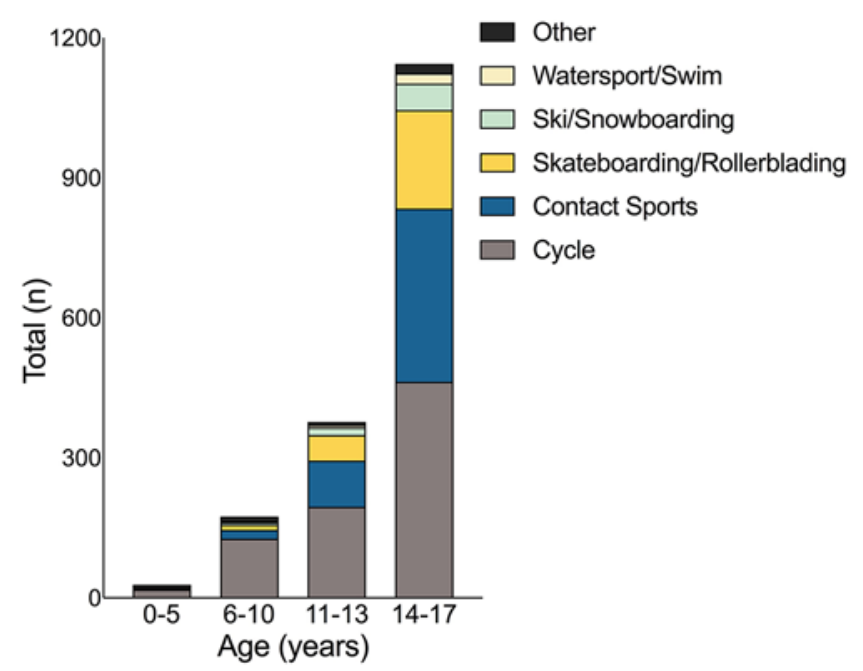

FIG. 1. Distribution of ages and sports-related mechanisms of injury in TSIs. $n=$ number of patients. Figure is available in color online only.

\section{Subgroup Analysis}

Subgroup analyses of 12,570 patients $0-9$ years old and 33,439 patients 10-17 years old were conducted (Table 2). In both age groups, TSI patients with and without SCI were more likely to have longer stays, to be discharged to or with rehabilitation, and to die than the patients without TSI (all $\mathrm{p}<0.05$ except for ICU admission in patients 0-9 years old with TSI). Compared to TSI patients 10-17 years old, the TSI patients who were 0-9 years old tended toward having longer stays, requiring rehabilitation, and dying compared to patients in the same age group without TSIs ( $p>0.05$ ). Interestingly, $7.2 \%$ and $2.5 \%$ of TSI patients 0-9 and 10-17 years old, respectively, died within the hospitalization (compared to $0.6 \%$ and $0.5 \%$ for nonTSI patients in these age groups).

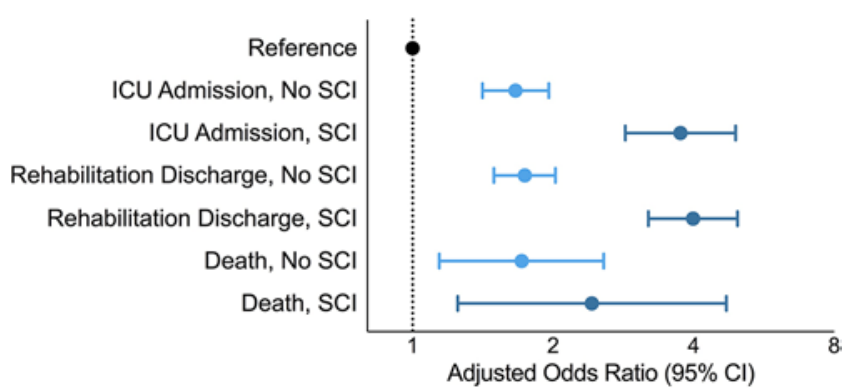

FIG. 3. Relative to pediatric sports-related non-TSIs (reference), TSIS without and with $\mathrm{SCl}$ were associated with an increased odds of ICU admission, rehabilitation discharge, and death/hospice disposition. Injuries with SCI were more likely to require ICU admission and rehabilitation. Figure is available in color online only.

\section{Discussion}

Pediatric TSI is associated with significant morbidity and mortality. Although pediatric TSI patients are more likely to recover than adult TSI patients, long-term neurological dysfunction has been estimated to be present in up to $60 \%$ of these pediatric patients, with mortality as high as $40 \% .^{1,9,22}$ Additionally, patients who have TSI before their adolescent growth spurt have a high likelihood of later developing scoliosis. ${ }^{12,33}$ TSI patients in this study were significantly more likely to require rehabilitative care after discharge than non-TSI patients. This effect was stronger for TSI patients with SCI than those without. Up to a quarter of sports-related pediatric TSI cases had SCI and approximately one-third needed ICU-level care.

Significant risk factors for needing rehabilitative care included surgical intervention, concomitant lower-extremity injury, head injury, and thoracic injury. Surgical intervention, indicated in unstable injuries and for decompression of neural structures, has not been associated with long-term effects including growth arrest in pediatric

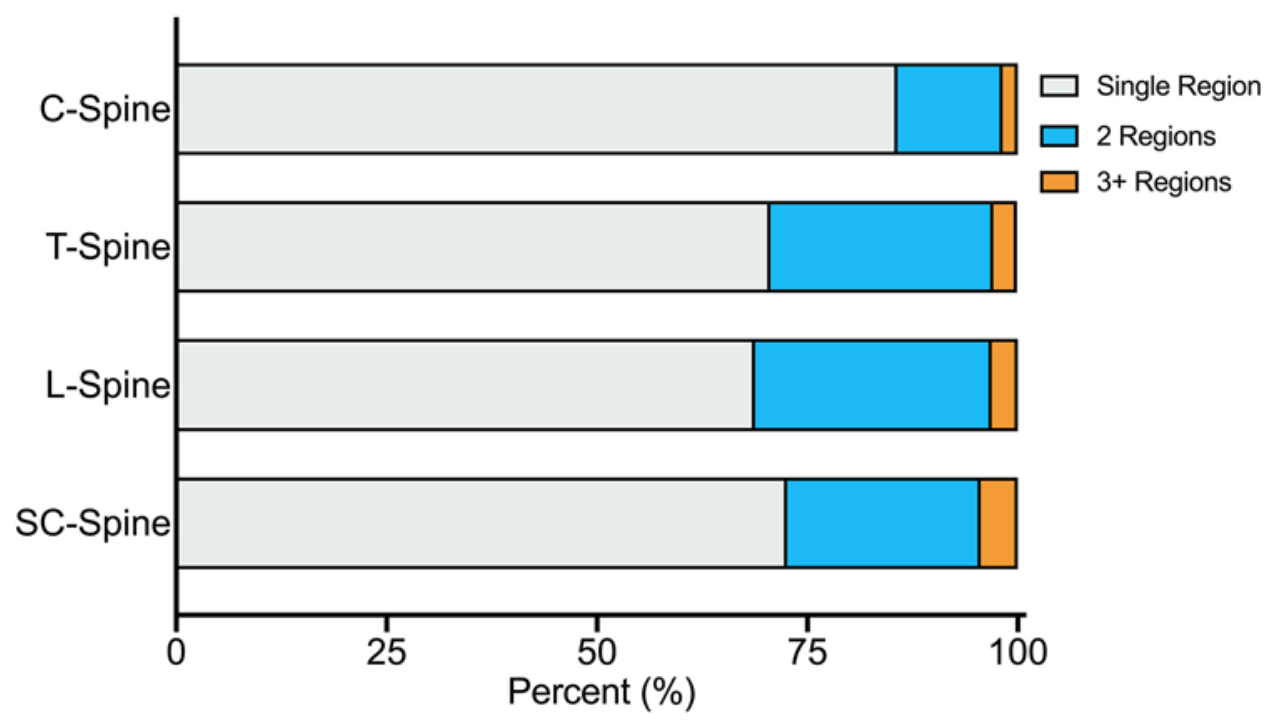

FIG. 2. The distribution of TSI regions affected, including the cervical spine (C-Spine), thoracic spine (T-Spine), lumbar spine (L-Spine), and sacral spine and coccyx (SC-Spine). Figure is available in color online only. 
TABLE 2. Subgroup analyses of TSI patients compared to non-TSI patients with sports-related injuries

\begin{tabular}{|c|c|c|c|c|c|c|}
\hline \multirow[b]{2}{*}{ Outcome } & \multicolumn{3}{|c|}{$\mathrm{NoSCl}$} & \multicolumn{3}{|c|}{$\mathrm{SCl}$} \\
\hline & OR & $95 \% \mathrm{Cl}$ & p Value & OR & $95 \% \mathrm{Cl}$ & $p$ Value \\
\hline \multicolumn{7}{|l|}{ Ages $0-9$ yrs old } \\
\hline Length of stay & $2.09^{*}$ & $1.34-2.84$ & $<0.001$ & $8.01^{*}$ & $6.47-9.56$ & $<0.001$ \\
\hline ICU admission & 1.61 & $1.00-2.61$ & 0.050 & 1.86 & $0.68-5.14$ & 0.227 \\
\hline Rehabilitation required & 1.88 & $1.19-2.97$ & 0.007 & 6.16 & $2.76-13.75$ & $<0.001$ \\
\hline Death & 2.71 & $1.06-6.95$ & 0.037 & 5.24 & $1.19-23.13$ & 0.028 \\
\hline \multicolumn{7}{|l|}{ Ages $10-17$ yrs old } \\
\hline Length of stay & $1.80^{*}$ & $1.59-2.00$ & $<0.001$ & $1.78^{*}$ & $1.44-2.13$ & $<0.001$ \\
\hline ICU admission & 1.60 & $1.33-1.92$ & $<0.001$ & 3.95 & $3.09-5.03$ & $<0.001$ \\
\hline Rehabilitation required & 1.73 & $1.47-2.05$ & $<0.001$ & 3.97 & $3.16-4.99$ & $<0.001$ \\
\hline Death & 1.68 & $1.07-2.64$ & 0.022 & 2.31 & $1.05-5.06$ & 0.036 \\
\hline
\end{tabular}

* Effect sizes for increases in length of stay with TSIs are included here rather than odds ratios.

spine patients. ${ }^{2}$ Concomitant lower-extremity and thoracic injuries have also been associated with a prolonged length of stay in adult TSI. ${ }^{8}$ These kinds of concomitant injuries can render a patient acutely immobile and possibly alter long-term mechanical loading more so than blunt abdominal trauma, for example?

Race and insurance status were not associated with discharge to or with rehabilitation in an adjusted model. This finding suggests that discharge disposition is not affected by these demographic factors or that disparities in outcomes across socioeconomic strata are seen prior to hospital presentation (i.e., on-site mortality, delays in accessing care) or after discharge (i.e., long-term functional status), rather than at the time of discharge. Higher injury mortality rates in pediatric patients with a low socioeconomic status have been partially explained by a higher incidence of trauma and more fatal mechanisms rather than by greater injury severity or worse inpatient care. ${ }^{28}$

Risk factors for in-hospital mortality included concomitant head injury, thoracic injury, and hypotension on presentation. This finding suggests that TSI patients with concomitant TBI or hemodynamic instability are at significant risk for a poor outcome. From the lens of TBI, concomitant injuries-which included TSI-have been shown to be associated with higher mortality. ${ }^{25}$

Notably, the most common mechanism of injury in our study was cycling accidents. One study in the adult population has indicated an increase in the number of cyclingrelated accidents and hospitalizations from 1998 to $2013 .{ }^{39}$ In that same study, $65 \%$ of injuries were in male patients, consistent with a male majority in our analysis. One possible explanation is that males are more likely to pursue less safe cycling habits..10,19 Given that cycling was the major mechanism of injury overall, societal investment is needed to better understand and enhance road safety for cyclists. ${ }^{6}$ These injuries continue to occur despite significant societal focus on cycling safety, particularly efforts to encourage helmet use. Consequently, further study to investigate adherence to current guidelines and regulations preceding TSI is necessary to determine the efficacy of these recommendations and whether additional policy interventions are indicated. Similarly, this analysis could yield insight into the efficacy of existing concussion prevention and other safety guidelines in patients who sustain TSI through contact sports.

Young children (age $<8$ years) most commonly incur TSI after motor vehicle accidents. ${ }^{26}$ In older pediatric patients, however, sports-related TSI becomes more common, especially in males. ${ }^{3}$ This is at least partially attributable to the fact that in the contemporary United States, males are more likely to partake in physically competitive sports, which also likely explains why the majority of this study cohort is male. ${ }^{11}$

Studies have suggested that the most common location of TSI in the pediatric population is the cervical spine. ${ }^{2,14,23,24,27}$ However, our study highlights the thoracic spine as the most common site of TSI among sports-related injuries, which may reflect the predominantly adolescent cohort studied. Many studies have found associations with cervical spine injuries in pediatric patients younger than 2 years of age. ${ }^{26,31,34,36,38}$ This finding is in part attributable to the higher fulcrum, larger head, and unfused synchondroses commonly at the site of the dens in younger children. ${ }^{4}$ As children get older and their cervical spines stabilize, it becomes more common to see thoracolumbar injuries as they become adolescents and adults..$^{15}$ This hypothesis is further supported by the median patient age of 15 years in our analysis, which could explain why slightly more thoracic injuries were seen than cervical.

This study has pertinent limitations related to the data source and study design. Included cases had injuries diagnosed with imaging; however, some TSIs occur without any appreciable radiological anomalies. Notably, spinal cord injury without radiographic abnormality (SCIWORA) was found to occur in $6 \%$ of pediatric TSIs in one study, indicating that our study may be biased by not including these cases. ${ }^{9,32}$ Furthermore, the accessed database may underestimate mortality, as patients who did not survive long enough to reach the hospital are not included. Multiple imputation requires missing values to be imputed using known data, which can be biased if there are unmeasured predictors of missingness. Further, the gold-standard outcome of interest in TSI is long-term functional outcome, which is not captured by these data. 
The strengths of this study derive from its large cohort size and the various data contained within the NTDB. The multicenter nature of the database provides excellent generalizability of the results and improves its validity. However, given the mean age of 15 in the TSI cohort, the conclusions of this study may be most applicable to adolescents rather than younger pediatric patients. Still, despite largely confirming previous findings regarding the increased morbidity of patients with TSI and the increased resources required to care for them, this study provides a distinct advantage for future advocacy, funding, and policy considerations by quantifying these trends in a large, nationwide cohort.

The major implication of this work is to identify the importance of preventing sports-related TSI in pediatric and adolescent patients. This includes analyses to determine whether current policies aimed at reducing TSI, such as helmet use guidelines and regulations pertaining to cycling, are typically adhered to in the setting of pediatric and adolescent TSI. This can inform future policy directions for both governmental and nongovernmental organizations to optimize injury prevention going forward.

\section{Conclusions}

Traumatic sports-related spine injuries, especially those with SCI, were associated with longer lengths of stay, a greater need for ICU-level care, a rehabilitation requirement at discharge, and in-hospital mortality, demonstrating a significant burden in the pediatric population. The majority of pediatric patients with sports-related TSI are males who were involved in cycling or contact sports injuries, which may be targets for designing educational and public health initiatives to reduce the incidence of injury from these activities.

\section{Acknowledgments}

We acknowledge support from the following grants: National Institutes of Health (NIH) T32 CA009001 (D.J.C.) and National Institute of General Medical Sciences T32 GM007753 (B.M.H.).

\section{References}

1. Akbarnia BA: Pediatric spine fractures. Orthop Clin North Am 30:521-536, x, 1999

2. Basu S: Spinal injuries in children. Front Neurol 3:96, 2012

3. Bilston LE, Brown J: Pediatric spinal injury type and severity are age and mechanism dependent. Spine (Phila Pa 1976) 32:2339-2347, 2007

4. Booth TN: Cervical spine evaluation in pediatric trauma. AJR Am J Roentgenol 198:W417-W425, 2012

5. Brown RL, Brunn MA, Garcia VF: Cervical spine injuries in children: a review of 103 patients treated consecutively at a level 1 pediatric trauma center. J Pediatr Surg 36:11071114, 2001

6. Buehler R, Pucher J: Trends in walking and cycling safety: recent evidence from high-income countries, with a focus on the United States and Germany. Am J Public Health 107:281-287, 2017

7. Butowicz CM, Dearth CL, Hendershot BD: Impact of traumatic lower extremity injuries beyond acute care: movementbased considerations for resultant longer term secondary health conditions. Adv Wound Care (New Rochelle) 6:269278,2017
8. Chu D, Lee YH, Lin CH, Chou P, Yang NP: Prevalence of associated injuries of spinal trauma and their effect on medical utilization among hospitalized adult subjects - a nationwide data-based study. BMC Health Serv Res 9:137, 2009

9. Cirak B, Ziegfeld S, Knight VM, Chang D, Avellino AM, Paidas CN: Spinal injuries in children. J Pediatr Surg 39:607-612, 2004

10. Davison CM, Torunian M, Walsh P, Thompson W, McFaull S, Pickett W: Bicycle helmet use and bicycling-related injury among young Canadians: an equity analysis. Int J Equity Health 12:48, 2013

11. Deaner RO, Geary DC, Puts DA, Ham SA, Kruger J, Fles E, et al: A sex difference in the predisposition for physical competition: males play sports much more than females even in the contemporary U.S. PLoS One 7:e49168, 2012

12. Dearolf WW III, Betz RR, Vogel LC, Levin J, Clancy M, Steel HH: Scoliosis in pediatric spinal cord-injured patients. J Pediatr Orthop 10:214-218, 1990

13. DeVivo MJ, Vogel LC: Epidemiology of spinal cord injury in children and adolescents. J Spinal Cord Med 27 (Suppl 1):S4-S10, 2004

14. Eubanks JD, Gilmore A, Bess S, Cooperman DR: Clearing the pediatric cervical spine following injury. J Am Acad Orthop Surg 14:552-564, 2006

15. Gertzbein SD: Scoliosis Research Society. Multicenter spine fracture study. Spine (Phila Pa 1976) 17:528-540, 1992

16. Green RS, Butler MB, Kureshi N, Erdogan M: A retrospective evaluation of pediatric major trauma related to sport and recreational activities in Nova Scotia. CJEM 18:106-111, 2016

17. Haider AH, Saleem T, Leow JJ, Villegas CV, Kisat M, Schneider EB, et al: Influence of the National Trauma Data Bank on the study of trauma outcomes: is it time to set research best practices to further enhance its impact? J Am Coll Surg 214:756-768, 2012

18. Hamilton MG, Myles ST: Pediatric spinal injury: review of 174 hospital admissions. J Neurosurg 77:700-704, 1992

19. Harlos S, Warda L, Buchan N, Klassen TP, Koop VL, Moffatt ME: Urban and rural patterns of bicycle helmet use: factors predicting usage. Inj Prev 5:183-188, 1999

20. Honaker J, King G, Blackwell M: Amelia II: a program for missing data. J Stat Softw 45:1-47, 2011

21. Hurtuk M, Reed RL II, Esposito TJ, Davis KA, Luchette FA: Trauma surgeons practice what they preach: the NTDB story on solid organ injury management. J Trauma 61:243-255, 2006

22. Hutchings L, Willett K: Cervical spine clearance in pediatric trauma: a review of current literature. J Trauma 67:687-691, 2009

23. Junewick JJ: Cervical spine injuries in pediatrics: are children small adults or not? Pediatr Radiol 40:493-498, 2010

24. Kokoska ER, Keller MS, Rallo MC, Weber TR: Characteristics of pediatric cervical spine injuries. J Pediatr Surg 36:100-105, 2001

25. Leitgeb J, Mauritz W, Brazinova A, Majdan M, Wilbacher I: Impact of concomitant injuries on outcomes after traumatic brain injury. Arch Orthop Trauma Surg 133:659-668, 2013

26. Leonard JR, Jaffe DM, Kuppermann N, Olsen CS, Leonard JC: Cervical spine injury patterns in children. Pediatrics 133:e1179-e1188, 2014

27. Lykissas M, Gkiatas I, Spiliotis A, Papadopoulos D: Trends in pediatric cervical spine injuries in the United States in a 10-year period. J Orthop Surg (Hong Kong) 27:2309499019834734, 2019

28. Marcin JP, Schembri MS, He J, Romano PS: A populationbased analysis of socioeconomic status and insurance status and their relationship with pediatric trauma hospitalization and mortality rates. Am J Public Health 93:461-466, 2003 
29. Maxfield BA: Sports-related injury of the pediatric spine. Radiol Clin North Am 48:1237-1248, 2010

30. Mez J, Daneshvar DH, Kiernan PT, Abdolmohammadi B, Alvarez VE, Huber BR, et al: Clinicopathological evaluation of chronic traumatic encephalopathy in players of American Football. JAMA 318:360-370, 2017

31. Mohseni S, Talving P, Branco BC, Chan LS, Lustenberger $\mathrm{T}$, Inaba $\mathrm{K}$, et al: Effect of age on cervical spine injury in pediatric population: a National Trauma Data Bank review. J Pediatr Surg 46:1771-1776, 2011

32. Pang D, Wilberger JE Jr: Spinal cord injury without radiographic abnormalities in children. J Neurosurg 57:114-129, 1982

33. Parent S, Mac-Thiong JM, Roy-Beaudry M, Sosa JF, Labelle $\mathrm{H}$ : Spinal cord injury in the pediatric population: a systematic review of the literature. J Neurotrauma 28:1515-1524, 2011

34. Patel JC, Tepas JJ III, Mollitt DL, Pieper P: Pediatric cervical spine injuries: defining the disease. J Pediatr Surg 36:373376, 2001

35. Piatt JH Jr: Pediatric spinal injury in the US: epidemiology and disparities. J Neurosurg Pediatr 16:463-471, 2015

36. Platzer P, Jaindl M, Thalhammer G, Dittrich S, Kutscha-Lissberg F, Vecsei V, et al: Cervical spine injuries in pediatric patients. J Trauma 62:389-396, 2007

37. Polk-Williams A, Carr BG, Blinman TA, Masiakos PT, Wiebe DJ, Nance ML: Cervical spine injury in young children: a National Trauma Data Bank review. J Pediatr Surg 43:1718-1721, 2008

38. Poorman GW, Segreto FA, Beaubrun BM, Jalai CM, Horn SR, Bortz CA, et al: Traumatic fracture of the pediatric cervical spine: etiology, epidemiology, concurrent injuries, and an analysis of perioperative outcomes using the Kids' Inpatient Database. Int J Spine Surg 13:68-78, 2019

39. Sanford T, McCulloch CE, Callcut RA, Carroll PR, Breyer $\mathrm{BN}$ : Bicycle trauma injuries and hospital admissions in the United States, 1998-2013. JAMA 314:947-949, 2015

40. Selassie AW, Wilson DA, Pickelsimer EE, Voronca DC, Williams NR, Edwards JC: Incidence of sport-related traumatic brain injury and risk factors of severity: a population-based epidemiologic study. Ann Epidemiol 23:750-756, 2013
41. Wang MY, Hoh DJ, Leary SP, Griffith P, McComb JG: High rates of neurological improvement following severe traumatic pediatric spinal cord injury. Spine (Phila Pa 1976) 29:14931497, E266, 2004

42. Winkler EA, Yue JK, Burke JF, Chan AK, Dhall SS, Berger MS, et al: Adult sports-related traumatic brain injury in United States trauma centers. Neurosurg Focus 40(4):E4, 2016

\section{Disclosures}

Dr. Chi is a consultant for $\mathrm{K} 2 \mathrm{M}$ and received clinical or research support from Spineology for the study described. Dr. Groff is a consultant for DePuy Spine, NuVasive Spine, and SpineArt.

\section{Author Contributions}

Conception and design: Gupta, Hauser, Xu, Cote, Khawaja, Smith Acquisition of data: Gupta, Hauser, Xu, Khawaja, Smith. Analysis and interpretation of data: Gupta, Hauser, Zaki, Xu, Cote, Lu, Chi, Groff, Khawaja, Harris, Zaidi. Drafting the article: Gupta, Hauser, Zaki, Cote, Khawaja, Zaidi. Critically revising the article: Gupta, Hauser, Zaki, Xu, Cote, Lu, Chi, Groff, Khawaja, Harris, Zaidi. Reviewed submitted version of manuscript: all authors. Approved the final version of the manuscript on behalf of all authors: Gupta. Statistical analysis: Gupta, Hauser, Xu, Cote, Smith. Administrative/technical/material support: Xu, Cote, Lu, Khawaja, Harris, Smith, Zaidi. Study supervision: Lu, Chi, Groff, Khawaja, Harris, Smith, Zaidi.

\section{Supplemental Information}

Online-Only Content

Supplemental material is available with the online version of the article.

Supplemental Appendix 1. https://thejns.org/doi/suppl/10.3171/ 2019.10.SPINE19712.

\section{Correspondence}

Saksham Gupta: Brigham and Women's Hospital, Harvard Medical School, Boston, MA.sgupta@bwh.harvard.edu. 